\title{
Copper Catalyzed C-O and C-N Coupling of Vinyl Bromides with Phenols and Azoles
}

\section{Jones Limberger and Adriano Lisboa Monteiro*}

Laboratory of Molecular Catalysis -Instituto de Química - UFRGS - Av. Bento Gonçalves, 9500, Porto

Alegre-RS, 91501-970 - CP 15003 - Brazil.

*adriano.monteiro@ufrgs.br

Keywords:C-O coupling, Vinylation, Copper

\section{INTRODUCTION}

In the past years significant improvements were achieved for the copper-catalyzed C-O and C-N coupling reactions ${ }^{1}$. The use of appropriate ligands allowed the efficiently coupling reaction under mild conditions and low catalyst loadings. Therefore, important building blocks of organic synthesis can be selectively produced. In this context vinylethers and vinylamines can be easily obtained through the coupling of phenols/azoles with vinyl halides. In present work, we performed the coupling of substituted phenols and azoles with (E)bromostilbene and bromotriphenylethene using a simple catalytic system composed by $\mathrm{Cul}$ and phenantroline. By using this protocol we were able to produce tri- and tetra-substituted vinylethers and vinylamines in good to excellent yields (Scheme 1).
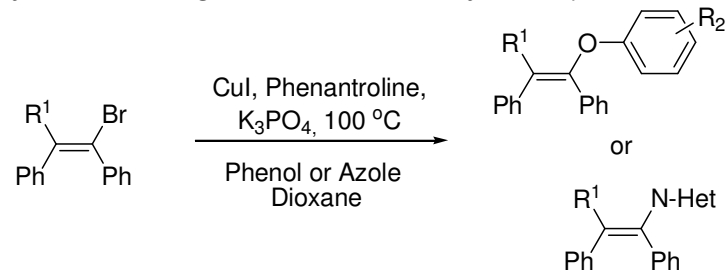

Scheme 1: Cul/Phenantroline catalyzed coupling of phenol and azoles with vinyl halides

\section{RESULTS AND DISCUSSION}

At first, we investigated the best reaction conditions using the coupling of $(E)$-bromostilbene with 4-tertbutylphenol as reaction model. We started using the same protocol described for the coupling of $\beta$ bromostyrene with phenols (Cul/picolinic imines and $\left.\mathrm{Cs}_{2} \mathrm{CO}_{3}\right)^{2}$, however, to our delight the best results were obtained by using a simple and inexpensive system composed by Cul/Phenantroline and $\mathrm{K}_{3} \mathrm{PO}_{4}$. After optimization, the scope of reaction was extent to a variety of phenols. With both electron rich and neutral phenols (Table 1, entries 1-2) excellent yields were obtained. With electron deficient phenols two different behaviors were observed: (i) phenols with slight electron-withdrawing groups coupled efficiently (entry 3 ); (ii) phenols with strong electronwithdrawing groups shown lack of reactivity, giving moderate yields (entry 4). In terms of steric hindrance, no remarkable decrease in the $14^{\text {th }}$ Brazilian Meeting on Organic Synthesis - 14 $4^{\text {th }}$ BMOS - September 01-05, 2011-Brasilia, Brazil conversion was observed using the hindered ortosubstituted phenol (entry 5). However, higher reaction time $(24 \mathrm{~h})$ was necessary to coupling the bromotriphenylethene and 4-methoxyphenol.

Table 1. Results of Copper catalyzed C-O e C-N couplings $^{\mathrm{a}}$

\begin{tabular}{ccccc}
\hline Entry & $\mathrm{R}^{1}$ & $\mathrm{R}^{2}$ or azole & Conv. (\%) & ${\text { Yield }(\%)^{\mathrm{b}}}^{2}$ \\
\hline 1 & $\mathrm{H}$ & $4-\mathrm{OMe}$ & 97 & 83 \\
3 & $\mathrm{H}$ & $\mathrm{H}$ & 99 & 91 \\
4 & $\mathrm{H}$ & $4-\mathrm{Br}$ & 100 & 82 \\
5 & $\mathrm{H}$ & $4-\mathrm{CN}$ & 61 & 49 \\
$6^{\mathrm{c}}$ & $\mathrm{Ph}$ & $4-\mathrm{Me}$ & 90 & 74 \\
$7^{\mathrm{c}}$ & $\mathrm{H}$ & Pyrazole & 85 & 79 \\
$8^{\mathrm{c}}$ & $\mathrm{H}$ & Imidazole & 56 & 46
\end{tabular}

a'Vinyl bromide $(2,0 \mathrm{mmol})$, phenol/azole $(3.0 \mathrm{mmol}), \mathrm{K}_{3} \mathrm{PO}_{4} \cdot \mathrm{H}_{2} \mathrm{O}$ (4 mmol), Cul $(10 \mathrm{~mol} \%)$, Fenantroline $(10 \mathrm{~mol} \%)$, Dioxane $(8$ $\mathrm{mL}), 6 \mathrm{~h} .{ }^{b}$ Isolated yield. ${ }^{\circ}$ reaction time: $24 \mathrm{~h}$.

Next, the same catalytic system was applied successfully to coupling bromostilbene with pyrazole and imidazole (entries 7-8). Therefore the corresponding vinylamines were obtained with moderate to good yields.

\section{CONCLUSION}

In summary, we developed a simple and efficient copper-based catalytic system that allow to coupling phenols and azoles with substituted vinylbromides affording vinylethers and vinylamines in good to excellent yields.

\section{ACKNOWLEDGEMENTS}

We thank CNPq, PRONEX and INCT-Catalise for financial support. We also thank CNPq (J. L.) for scholarship.

\section{REFERENCES}

${ }^{1}$ Monnier, F.; Taillefer, M. Angew. Chem. Int. Ed. 2009, 48, 6954

2 Taillefer, M.; Ouali, A.; Renard, B.; Spindler, J. F. Chem. Eur. J. 2006, 12 , 5301. 